\title{
Proceeding
}

8th INSHS International Christmas Sport Scientific Conference, 5-7 December 2013. International Network of Sport and Health Science. Szombathely, Hungary

\section{The neurofeedback course using of high skilled gymnasts at competitive period}

\author{
OLGA STRIZHKOVA , LARISA CHERAPKINA, TATIANA STRIZHKOVA \\ Chair of anatomy, physiology, sport medicine and hygiene, Siberian State University Of Physical Culture And Sport, Russia
}

\begin{abstract}
Strizhkova, O., Cherapkina, L. \& Strizhkova, T. (2014). The neurofeedback course using of high skilled gymnasts at competitive period. J. Hum. Sport Exerc., 9(Proc1), pp.S561-S569. The research was carried out with 28 high skilled gymnasts (15 - main group, 13 - control group) allowed to define the neurofeedback influence on the functional condition of sportswomen in competitive period. The neurofeedback course promotes improvement of rapidity of complex coordinating motions learning, vestibular stability and self-estimation of functional condition. Also it conducts the alpha-rhythm power increasing at left hemisphere. The neurofeedback course efficiency is defined by index of change of course average alpha-rhythm power with $100 \%$ prognostic accuracy. The attention switching, attention stability and self-estimation of sleep and memory are predictors of neurofeedback course successfulness. Key words: EFFICIENCY OF TRAINING, SUCCESSFULNESS OF TRAINING, CEREBRUM BIOELECTRIC ACTIVITY, PREDICTORS OF EFFICIENCY AND SUCCESSFULNESS.
\end{abstract}

Corresponding author. Chair of anatomy, physiology, sport medicine and hygiene, Siberian State University Of Physical E-mail: strizhi85@mail.ru

8th INSHS International Christmas Sport Scientific Conference, 5-7 December 2013. International Network of Sport and Health Science. Szombathely, Hungary.

JOURNAL OF HUMAN SPORT \& EXERCISE ISSN 1988-5202

(c) Faculty of Education. University of Alicante

doi:10.14198/jhse.2014.9.Proc1.47 


\section{INTRODUCTION}

Achievement by sportsmen the certain purposes carries out during endo- and exogenous stress-factors permanent influence on their functional systems (Solodkov, 1995; Shagiev, 2009). In this context there is a burning issue about searching of methods of unmedicamental influence on adaptation processes (Kuz'min, 2010). The designing and adoption of methods based on the development of selfregulation capacities in sportsmen takes on special significance (Denisenko et al., 2008). Biofeedback is one of such methods, which promotes generation of functional parameters changes and creation of complex reactions in central and vegetative nervous system (Soroko \& Trubachiov, 2010).

Neurofeedback is one of the most perspective methods, which is based on biofeedback (Fedotchev, 2010; Lubar et al., 1995; Angelakis et al., 2007). This method implies person's self-regulation by cerebrum bioelectric activity, particularly by alpha-rhythm (Bazanova, 2009). Neurofeedback gives the objective information about dynamic of psychophysiological indexes and allows executing the extra sensory supervision of the physiological process (Fedotchev \& Bondar, 2008). Among the neurofeedback advantages there is an utmost personalization and subject's active participation in his condition optimization (Fedotchev, 2010).

Increasing of successfulness of competition activity is the most important purpose of training process in all sports types (Radcliffe, 2007). For one's turn the successfulness of competition activity is determined by optimization efficiency of training process constituents (physiological, psychological, biomechanical and tactical) and by life pattern (Smith, 2003; Blumenstein et al., 2007).

According to Thompson's et al. supposition (2008) successful neurofeedback can promote increasing of sportsmen's competition successfulness by rearrangement of EEG pattern.

How ever at present the question about neurofeedback influence on competition results is studied not enough.

\section{MATERIALS AND METHODS}

Forty-six sportswomen from 16 till 21 years old (average age 18 $\pm 0,1$ years) took part on the research (Table 1).

Table 1. Sharing of examined persons by sports specialization and age

\begin{tabular}{ccc}
\hline Sport specialization & Quantity of sportswomen & Age (years) \\
\hline Acrobatic Gymnastics & 22 & $18 \pm 0,3$ \\
Aerobic Gymnastics & 7 & $19 \pm 0,3$ \\
Rhythmic Gymnastics & 13 & $19 \pm 0,3$ \\
Artistic Gymnastics & 4 & $18 \pm 0,3$ \\
\hline
\end{tabular}

The neurofeedback was realized with using of software-hardware complex «Boslab», which was engineered in Institute of molecular biology and biophysics SB RAMS c. Novosibirsk. A monitoring session of indexes was carried out before neurofeedback session for control of accuracy of electrodes laying on. In our research we applied a neurofeedback course directed to increasing of alpha-rhythm power (F1; P3). 
Power of alpha-, beta-, theta-rhythms and raw electroencephalogram (EEG) of left hemisphere, as well as power of integrated electromyogram (EMG) was printed on working graphs during the neurofeedback sessions (Figure 1, 2). Sound signal of feedback appeared when two conditions were fulfilled concurrently: value of the main signal (power of alpha-rhythm) was higher than threshold level and value of interference EMG didn't exceed threshold level, which amounted $10 \mathrm{mcV}$. This criterion gave opportunity to except the signal appearance in case when the increasing of alpha-rhythm power was connected with muscles activity (movement of eyes and eyebrows, tension of mimic muscles etc.).

The neurofeedback course consisted of 15 sessions. The sessions were realized once in a day before workout. At each neurofeedback session the sportswomen were informed about successfulness of session and could estimate their capacity to selfregulation by bioelectrical activity of cerebrum (Pogodaeva, 2001).

During neurofeedback sessions sportswomen were in armchair with closed eyes, which continued 30 min. (Pogodaeva, 2001). Sportswomen didn't receive strict recommendations, but it was suggested to remember some images, sensations in body, experiences that connected with relaxation, rest and pleasure. At the same time they were recommended to listen to sound of signal, which appeared by exceeding of threshold level of alpha-rhythm power during $0,5 \mathrm{~s}$ and to try to connect the appearance of sound signal with one or another condition. If a sportswoman could induce „innerpsychological“ condition connected with more rapid sound signal and consequently to raise alpha-rhythm power, then she should keep this condition as long as possible until the sound signal was unbroken. As the work during the sessions became more efficient, the task of sportswoman became more difficult and the threshold level got heightened. The registration of EMG gave opportunity to define, that the sportswomen were in a state of relaxation (Shubina et al., 2010).

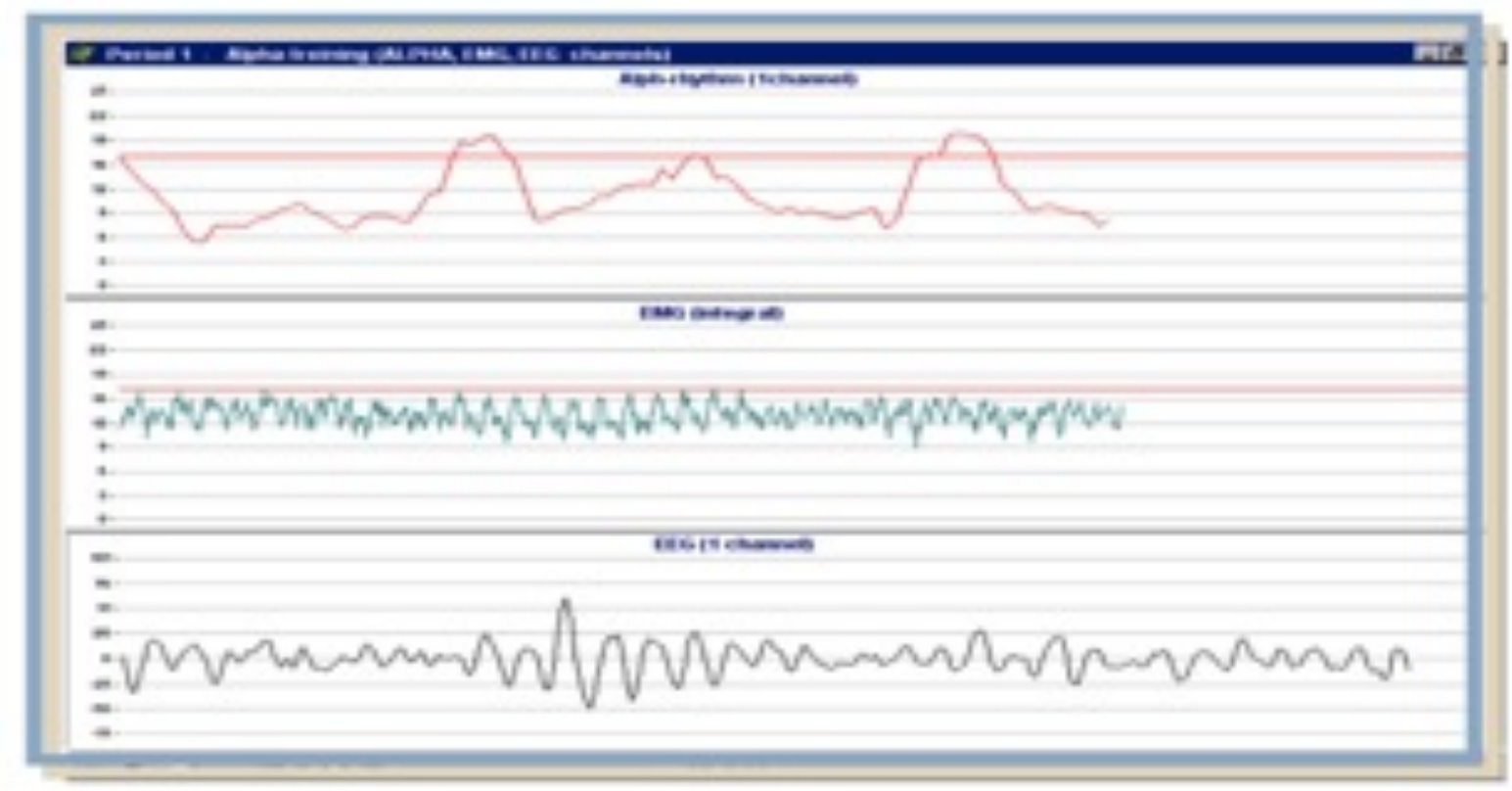

Figure 1. Form of the works graph during neurofeedback sessions directed to increasing of alpha-rhythm power during displaying of alpha-rhythm power, integrated EMG and raw EEG 


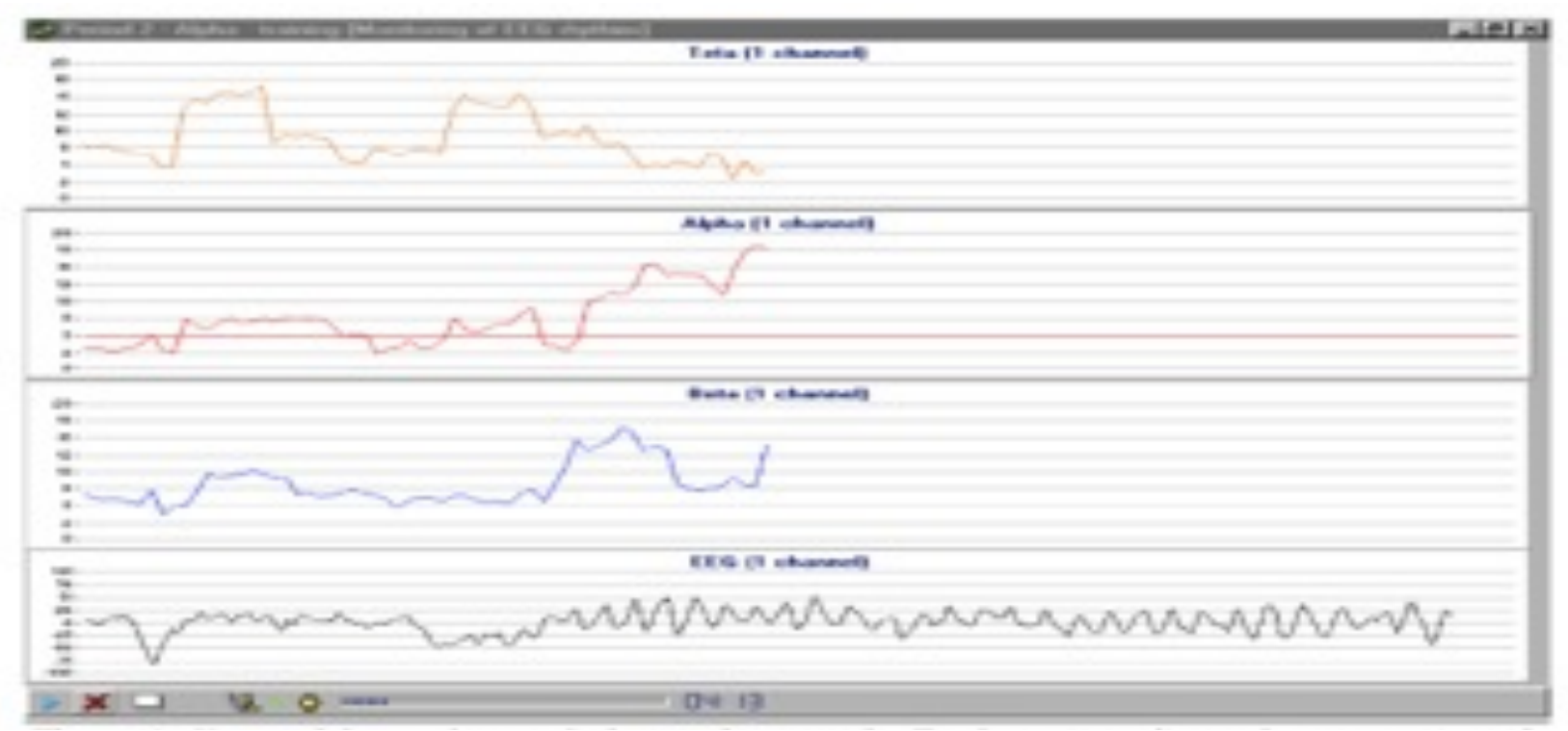

Figure 2. Form of the works graph during neurofeedback sessions directed to increasing of alpha-rhythm power during displaying of alpha-, beta-, theta-rhythms power and raw EEG

A main plan of our research with enumeration of methods is represented on a figure 3 .

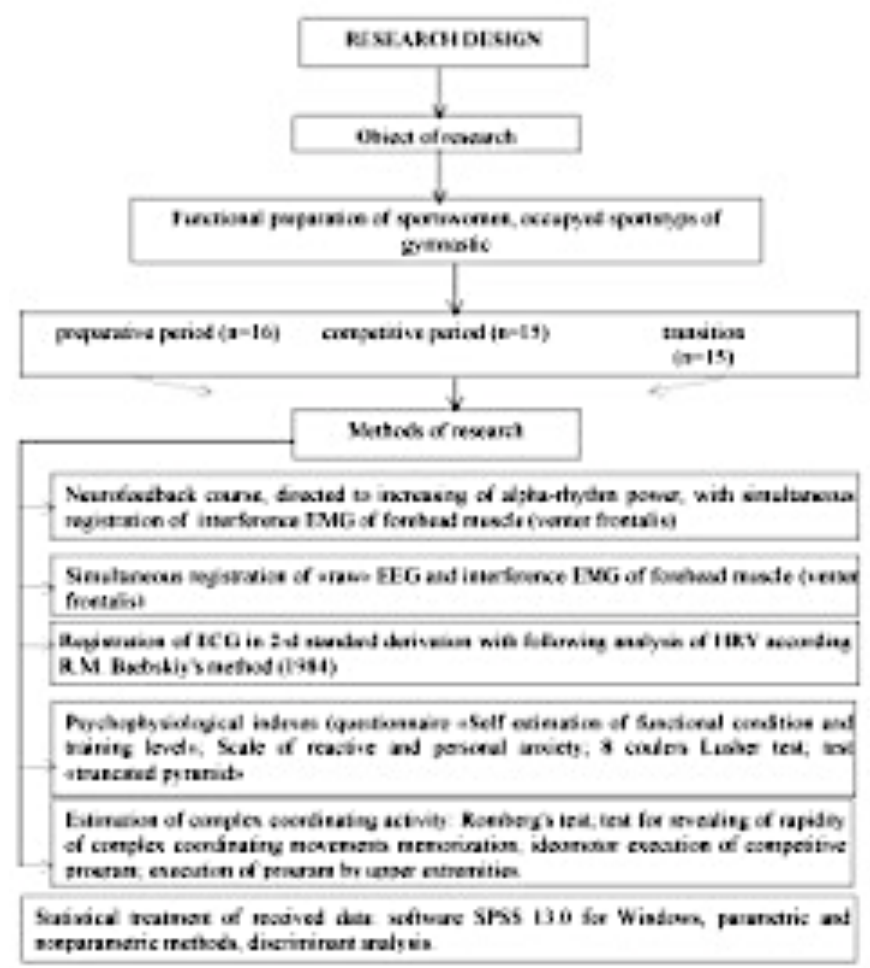

Figure 3. Design of the research 
During neurofeedback application the notions of successfulness and efficiency are differentiated. Changing of controllable parameters in the established direction comprehends as successfulness. Improvement of general functional condition of a human organism under the influence of the regulation of a hand-picked function comprehends as efficiency (Svyatogor, 2000).

The successfulness of the neurofeedback was expressed in a percentage ratio of sessions amount, where the alpha-rhythm power exceeded initial value on $15 \%$ and more, to general amount of carried out sessions (Svyatogor, 2000).

Indexes of heart rate variability, of complex coordinational activity and of psychophysiological condition, which were registered before the neurofeedback course, were compared with the same indexes, which were received after that for estimation of a summary index of the neurofeedback efficiency of each sportswoman. The neurofeedback course was considered as efficient one, when more then $30 \%$ of the researched indexes indicated improvement of functional condition of sportswomen. The course was considered inefficient, if after it using $30 \%$ of indexes and less improved.

Statistical treatment was held with program SPSS 13.0 for Windows (Nasledov, 2009). Normalcy of distribution was estimated by skewness and kurtosis criterions.

\section{RESULTS}

Estimation of EEG-activity of sportswomen registered during 15 sessions of neurofeedback directed on increasing of alpha-rhythm power revealed, that course average values of power of alpha-, beta-, thetarhythms registrated in different periods of training process did not have significant differences (Table 2).

In competitive period course average power of alpha-rhythm of left hemisphere was higher then value of this index in before the course "background“ EEG $(p<0,05)$. In transition period the course average power of alpha- and beta-rhythms exceeded the values of the indexes, which were received during the registration of the «background» EEG held before the neurofeedback course $(p<0,05)$. In sportswomen, which were in preparatory period, the course average values of bioelectrical activity indexes of left hemisphere did not differ from the indexes, received during before the course registration of «background» EEG.

Statistically significant differences between successfulness of neurofeedback course of sportswomen, underwent it in different periods of training process, were not revealed. According Svyatogor's et al. (2000) classification, in preparatory period successfulness of neurofeedback course corresponds to low level, but in competitive period and transition - middle level.

Table 2. Changes of left hemisphere rhythm power of cerebrum and neurofeedback course succeefulness in gymnasts women indifferent periods of training process, M:m. 


\begin{tabular}{|c|c|c|c|c|c|c|c|c|c|c|}
\hline Index & Theta-rhyth & m power i $n$ & $\mathrm{me} \mathrm{N}^{2}$ ) & Alpha- & $\begin{array}{l}\text { for then por } \\
\text { (mcit) }\end{array}$ & wer & Beta-d: & $\begin{array}{l}\text { trythes powe } \\
\text { (mev') }\end{array}$ & & $\begin{array}{c}\text { Success } \\
\text { fullness\% }\end{array}$ \\
\hline peried & 1 & 2 & $Z_{52}$ & I & 2 & $Z_{13}$ & 1 & 2 & $Z_{12}$ & \\
\hline $1(n=16)$ & $5,72 \pm 0,30$ & $5.91 \pm 0,20$ & -109 & $3.70=0.30$ & $3,93: 0,35$ & 0,36 & $363=023$ & $3,72 \pm 0,15$ & 0,47 & 53470 \\
\hline II $(n=15)$ & $5,4210,34$ & $5,71 \pm 0,24$ & $-1,31$ & $3.00=0.18$ & $3,65=0,21$ & $-1,99^{\circ}$ & $3.73=0,29$ & $3 \times 00=017$ & $-1,06$ & 40446 \\
\hline II $(n=15)$ & $6.1940,37$ & $5,7 \pm 0.13$ & 0,97 & $358=0.11$ & $3,09=0.17$ & $-205^{\circ}$ & $3,41+0,15$ & $3,93+0,11$ & $239^{\circ}$ & - $45,4,1$ \\
\hline
\end{tabular}

By means of $\chi 2$ criteria it was revealed, that in preparatory period a quantity of persons, who underwent the neurofeedback course successfuly, did not exceed a quantity of sportswomen, who underwent it unsuccessfuly $(p>0,05)$. From sixteen examined persons eight were «unsuccessful», at the same time the successfulness parameter of two sportswomen was equal to nil. In competitive period a group of «unsuccessful» consisted of five persons. Ten sportswomen underwent neurofeedback course successfully. Nevertheless groups of «successful» and «unsuccessful» in this period quantitatively did not differ $(p>0,05)$. In transition period, where 12 sportswomen underwent the neurofeedback course successfully and 3 - unsuccessfully, an amount of «successful» persons exceeded a quantity of «unsuccessful» significantly $(\mathrm{p}<0,05)$.

To summarize the influence of neurofeedback on HRV, complex coordinated activity and psychophysiological condition of gymnasts-women a summary index of neurofeedback course efficiency was used (figure 4). Statistically significant differences between preparative period and transition $(p<0,05)$ were revealed during comparative analysis of received data in different periods of training process. The highest index of efficiency was characteristic of transition period, where it amounted $52 \pm 4,1 \%$. In preparatory period the lowest index of efficiency was observed, which equaled $40 \pm 3,3 \%$. In competitive period the index of efficiency totaled $48 \pm 3,9 \%$ and did not different from the same indexes in other periods $(\mathrm{p}>0,05)$.

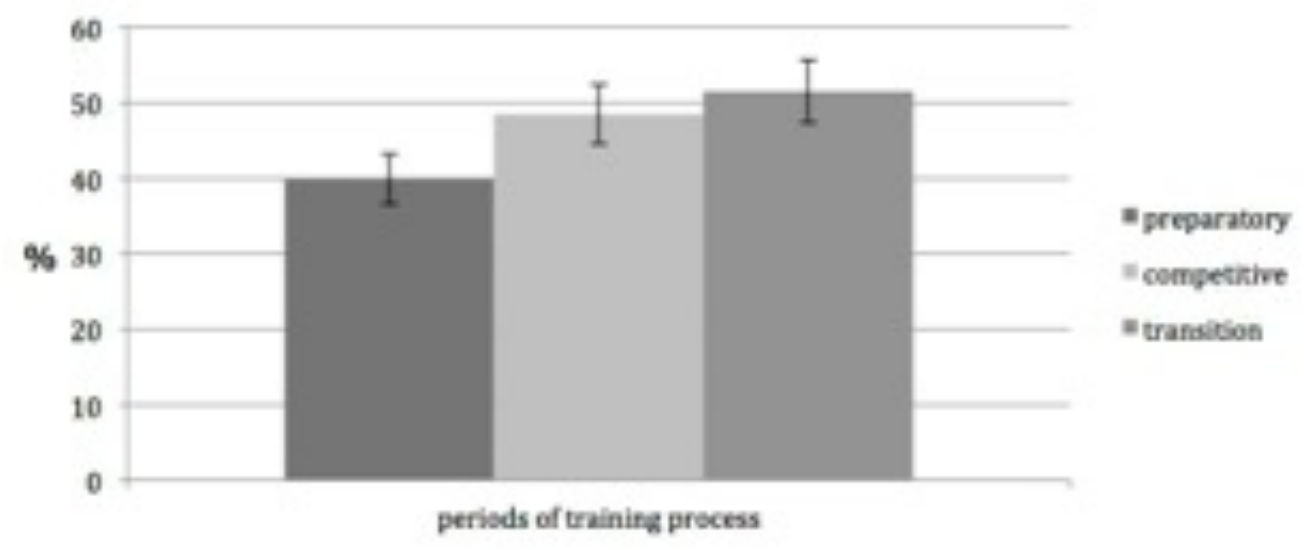

Figure 4. The indexes of neurofeedback efficiency indifferent periods of training process of gymnasts women

For analysis of sportswomen's competition successfulness a performance results in the main competition of year was accepted, which considered as successful, if the result exceeded the result achieved in the last competition of the same rank. 
According to received data of 46 gymnasts-women, who underwent the neurofeedback course, 21 sportswomen were able to improve their own competition result. As opposed to competitive $(p<0,0001)$ and transition $(p<0,005)$ period the preparatory period was characterized by the lowest amount of sportswomen, who improved sports results after the neurofeedback course. In competitive and transition period a quantity of sportswomen, who improved competitive result, was equal.

The carrying out of discriminant analysis did not reveal interconnection of competitive result with successfulness and efficiency of neurofeedback course in the each single period of training process. During annual training cycle the index of neurofeedback course successfulness was a factor, allowed to prognose the improvement of gymnasts' competitive result, independently on period of training process. In this case the equation of discriminant function looked in the following way:

$d=0,050^{*}$ course successfulness $-1,962$.

The average values of discriminant function differed from each other significantly $(\chi 2=6,299 ; \mathrm{p}<0,02)$ and equaled $-0,354$ - for absence of competitive result improvement and 0,421 - for increasing of competitive result. Coefficient of canonical correlation amounted 0,37 , with exactness of prognosis $72 \%$.

Efficiency of neurofeedback course of gymnasts-women was not the factor, which prognoses improvement of competitive result.

\section{DISCUSSION}

Course-average EEG-indexes analysis showed that in the competitive and transition periods gymnasts mastered the skill of self-regulation by alpha-rhythm power more successfully, where they were able to achieve significant gain of alpha-rhythm power relatively to its initial power in «background» EEG. This process appeared in the neurofeedback successfulness index of sportswomen in the competitive and transition periods.

According to successfulness estimation criterion (I.A. Svyatogor, 2000), chosen in this study, its value corresponded to middle level in the competitive and transition periods. In the preparatory period it corresponded to low level. In the transition period the number of sportswomen underwent neurofeedback course successfully exceeded the number of sportswomen underwent it not successfully.

The integral neurofeedback efficiency index reached the highest values in the competitive and transition periods. In the preparatory period neurofeedback course was the least effective. Conceivably, in the competitive period high neurofeedback efficiency and middle successfulness was conditional by the fact that as the athletics' shape gets more optimal, gymnasts master the skill of self-regulation by CNS functional condition more successfully. Here they were able to reach the alpha-rhythm increase during neurofeedback applying.

The highest neurofeedback course efficiency and middle successfulness in the transition period was connected with relatively high left hemisphere initial alpha-rhythm power in «background» EEG (Strizhkova et al., 2011). It is confirmed by the opinion that successfulness as well as efficiency depends on optimality of initial CNS functional condition (Svyatogor \& Mahovikova, 2002; Tristan et al., 2004). 
The analysis of sportswomen' sport results showed that the competitive and transition periods were characterized by the greatest number of sportswomen who improved this index. During annual training cycle independently on training process period the neurofeedback successfulness index was the factor, which allowed predicting the gymnasts' sport results improvement.

\section{CONCLUSIONS}

Thereby, in the competitive and transition periods sportswomen cope with the task of self-regulation by alpha-rhythm power with a highest successfulness.

In the competitive and transition periods neurofeedback course is the most efficient which is confirmed by highest integrated neurofeedback efficiency index.

Neurofeedback successfulness index possess high prognostic value for improvement of highly qualified sportswomen's sport results.

\section{REFERENCES}

1. Angelakis, E., Stathopoulou, S., Frymiare, L.J., Green, L.D., Lubar, F.J. \& Kounios, J. (2007). EEG neurofeedback: a brief overview and an example of peak alpha frequency training for cognitive enhancement in the elderly. The Clinical Neuropsychologist, 21(1), pp.110-129.

2. Bazanova, O.M. (2009). Individual charecteristics of alpha-activity and sensors integration. [Autor's abstract of Dis. of Doctor Biol. Scien]. Novosibirsk: State Institution of science-research institute of molecular biology and biophysics.

3. Blumenstein, B., Lidor. R. \& Tenenbaum, G. (2007). Psychological Factors of Technical Preparation. Psychology of Sport Training. Perspectives on Sport and Exercise Psychology, 2, pp.8-19.

4. Denisenko, Yu.P, Vysochin, Yu. V. \& Yatsenko, L.G. (2011). Contemporary conception about structural-functional organisation of neuro-muscular system and mechanisms of contraction and relaxation of skeletal muscles. Pedagogical-psychological and medical-biological problems of physical education and sport, 4(21), pp.39-49.

5. Fedotchev, A.I. (2010). About efficiency of biofeedback treatment with feedback from EEG of patient during correction of functional deseases, produced by stress. Human Physiology, 36(1), pp.100-105.

6. Fedotchev, A.I. \& Bondar', A.T. (2008). Method of duble feedback from EEG-rhythms of patients for correction of functional deseases, produced by stress. Journal of high neural activity of I.M. Pavlov's name: RAS, 58(3), pp.376-381.

7. Fokina, Yu.O., Pavlenko, B.V. \& Kulichenko, A.M. (2008). Possible mechanisms of biofeedback influence according to electroencefalogram. Memoirs of Tavricheskiy National university of V.I.Vernadskogo's name. Series «Biology, chemistry», V21, (60)1, pp.107-116.

8. Lubar, F.J. (1997). Neocortical dynamics: implication for understanding the role of neurofeedback and related techniques for the enhancement of attention. Appl Psychophys and Biof, 22(2), pp.111126.

9. Kuz'min, M.A. (2010). Study of influence of objective factors on adaptation of sportsmen to competitive activity in combat and art types of sport. Memoirs of university of P.F. Lesgaft's name, 12(70), pp.74-78. 
10. Pogadaeva, O.V. \& Tristan, V.G. (2001). The human notion about time after AST. Omsk: III AllRussian scientific conference of Biofeedback in medicine and sport, pp.48-49.

11. Radcliffe, J.C. (2007). Functional Training for Athletes at All Levels: Workouts for Agility, Speed and Power. Ulysses Press.

12. Shagiev, R.M. (2009). Structural-functional characteristics of stress-resistance in sports activity. [Autor's abstract of Dis. of Candidate of Psych. Scien]. Yaroslavl': Yaroslavskiy State University of P.G. Demidov's name.

13. Shubina, O.S., Mel'nikov. M.E. \& Veretel'nikov, I.A. (2010). Research of frequency range of cerebrum alpha-rhythm in patients with chronic headache of tension in temperatureelectromyographic biofeedback course. Bulletin of Siberian division of Russian academy of medical science, 2, pp.42-46.

14. Smith, D.J. (2003). A framework for understanding the training process leading to elite performance. Sports Med, 33(15), pp.1103-1126.

15. Solodkov, A.S. (1998). Problem of adaptation in sport: condition and perspectives of development. Moscow: International congress: Human in sport world: new ideas, technologies, perspectives, 1, pp.118-119.

16. Soroko, S.I. \& Trubatchov, V.V. (2010). Neurophysiological and psychophysiological bases of adaptive biofeedback. RAS. Institute of Russian academy of science. Institute of evolutionary physiology and biochemistry of I.M. Sechenov's name RAS. St. Petersburg.

17. Strizhkova, O.U., Strizhkova, T.U. \& Cherapkina, L.P. (2011). Changes of cerebrum bioelectrical activity in gymnasts in different periods of training process. Journal "Bulletin of Tyumen State University". Series "Medicine-biological sciences", 6, pp.166-170.

18. Svyatogor, I.A. (2000). The method of cerebrum potential biofeedback and clinical using of it. Biological, 1, pp.5-7.

19. Svyatogor, I.A. \& Mokhovnikova, I.A. (2002). Neurophysiological, psychological and clinical aspects of cerebral potentials biofeedback in patients with desadaptive diseases. Omsk: IV AllRussian scientific conference of Biofeedback in medicine and sport, pp.24-25.

20. Tristan, V.G., Pogodaeva, O.V. \& Tristan, V.V. (2004). Neurofeedback influence on psychophysiological indexes of sportsmen with different EEG-parameters. Bulletin of Siberian division of Russian academy of medical science, 1(111), pp.120-125. 